\title{
TEAM FORMATION IN ENGINEERING DESIGN COURSES
}

\author{
Mohamed Galaleldin, Justine Boudreau and Hanan Anis \\ University of Ottawa - Faculty of Engineering, 161 Louis Pasteur, Ottawa, Canada, K1N 6N5 \\ mgala028@uottawa.ca, jboud030@uottawa.ca, hanis@uottawa.ca
}

\begin{abstract}
Engineering design courses often include a team-based project. Project-based learning offers a great opportunity for engineering students to learn about teamwork and collaboration. It also gives students a chance to learn about themselves and improve their conflict management skills. Choosing the right team members for a specific project is not trivial, as the choice of the team often affects the project outcome and the students' experience in the course. Moreover, there is a debate among engineering educators as to whether it is better to force team composition or not. In this paper, we investigate the impact of team composition and formation on project outcomes and student satisfaction in a secondyear engineering design course at the University of Ottawa. The course is open to all engineering students and has an accessibility theme. Students work in teams with a client that has a specific accessibility need. Students meet the client three times during the semester and deliver a physical prototype by the end of the semester. For this study, students in the design course were divided into two groups. Students in the first group were allowed to pick their teams, while the instructor created the teams in the second group based on multidisciplinary composition and year of study. Both groups had the same instructor and the same course material, labs, project choices, etc. Semi-structured interviews were conducted with a few teams in each group.
\end{abstract}

Keywords: Teamwork, Project-Based Learning, Cornerstone Engineering Design Curriculum.

\section{INTRODUCTION}

Collaborative learning has long been advocated as a learning approach that increases students' interest in the subject matter, allows students to assume responsibility for their own learning and promotes critical thinking [1], [2]. There are many definitions of collaborative learning; one of the broadest definitions is that collaborative learning refers to "a situation in which two or more people learn or attempt to learn something together" [3, p. 1]. Compared with traditional learning environments that use instructor-centered lectures, individual assignments and competitive grading [4], collaborative learning courses that use small project groups are found to allow students to attain higher academic achievement, retain information longer, acquire better critical thinking skills, have lower levels of anxiety and stress, acquire greater communication and teamwork skills, have more positive interactions with peers and more positive attitude towards the subject area, and higher self-esteem[5], [6]. In relation to teamwork skills, small student groups allow students to familiarize themselves with the different roles in teams, the stages of team development and the norms of group work [7].

However, these benefits are conditional on students having positive team experiences and being part of an effective and functional team [6]. For student teams to result in an effective learning experience, students should be able to engage in conversations and discussions with their peers [8]. Factors that affect team dynamics include students' teamwork skills and whether they have received training on teamwork skills such as conflict resolution and communication, as well as team formation, team diversity, the occurrence of productivity or interpersonal problems [9] and team size [10]. This paper is concerned with approaches instructors use to form student teams in collaborative project-based-learning courses. Approaches to team formation can be summarized in three main categories: self-assignment, instructor assignment and random assignment [5], [11]. This paper aims to assess the impact of two of these approaches, self-assignment and instructor-assignment, on students' academic achievement.

Self-assignment provides advantages such as facilitating the initial cohesiveness that helps students to be productive at the beginning of the semester. It also encourages students to take ownership of group conflicts and problems and to benefit from past experience if the students have worked in a team environment before [12]. However, self-selection has its own disadvantages, as it 
can result in teams that lack diversity, are overly homogenous [10] and have an inadequate skillset [7]. Moreover, Oakley et al. [6, p. 11] have noted that from their experience, self-selected teams "have a higher propensity for cheating because pre-existing relationships between students with a common corner-cutting mindset can reinforce the belief within a group that 'it's okay everybody does it." The second approach considered in this study is instructor assignment. Widely different criteria can be used to assign students to teams, including students' personality type, learning style, gender and specialization [13].

This paper provides engineering educators with an experimental comparative study of the effects of two team formation approaches on students' academic achievement and their satisfaction with the course's learning experience. The first approach was allowing students to self-select their team members, and the second was having the instructor form teams on the basis of the students' complementary skills.

\section{INTRODUCTION TO ENGINEERING DESIGN AND PRODUCT DEVELOPMENT FOR ENGINEERS AND COMPUTER SCIENTISTS}

The course where student teams were studied is a second-year engineering design course taught at uOttawa. The course aims to situate students to learn engineering design in a client-centered learning experience where groups of students work on a specific engineering problem based on a client's needs during one semester, engage in a series of prototyping cycles and deliver a final functional prototype. Student teams are formed from multidisciplinary engineering and computer science students from different years of study within the first two weeks of class.

Throughout the course, students learn design methodologies, processes for product development, time and project management, business models, economics and marketing. The students put those skills to use in their own project, which starts with a small project description followed by a first meeting with their client, during which students aim to understand the client's needs through empathy. The team then develops concepts and metrics before meeting the client a second time to get feedback on their conceptual design. Once their conceptual design has been approved by the client, students start the prototype iteration cycle, during which they use facilities like the makerspace and the machine shop to make three or more prototypes to get to their final product. After they have finished their first prototype, students meet with their client for a third time, to receive more feedback on their prototype's features and functionality. The client is then presented with the final product at the end of the semester at Design Day, a showcase featuring all the cornerstone engineering design course's teams. This work is done mostly outside of scheduled class and lab time. Some lab time is dedicated to working on the project, while the rest of the lab time is used to introduce students to the use of engineering tools and software that could help them in creating their prototypes or in future projects at the school. Students are introduced to the use of technologies such as Arduino, 3D printing, soldering and sheet metal work. During each of these labs, students produce one part of a little mobile app-controlled chariot that is assembled in one of the last labs.

The theme for this course is accessibility, which means students work on projects like wheelchair skis, portable wheelchair ramps and foot-controlled guitars. Clients are diverse, ranging from individuals to organizations like hospitals, and all have different needs.

Each lab has a teaching assistant (TA) and a project manager (PM). The TA is typically a graduate student, and the PM is typically an undergraduate student who has taken the course before and has demonstrated exemplary leadership and technical skills in their own teams. The TA and PM both act as guides and mentors to the groups as they go through their design process and learn the skills necessary to complete their projects. Both sit together at the end of the semester and evaluate each student in their lab based on their contribution to the project over the semester.

At the start of the semester, to learn about their personalities, strengths and weaknesses, students complete an OCEAN personality assessment, which measures their openness to experience, conscientiousness, extraversion, agreeableness and neuroticism. Each team also completes a peer and team assessment twice in the semester using a tool developed by the Individual and Team Performance (ITP) Lab at the University of Calgary [14]. The first assessment happens in the sixth week of the semester, so the students are able to receive feedback from their teammates and improve on their designs before most of the heavy prototyping happens. The professor, TA and PM also use this initial assessment to identify 
student teams that are struggling and require their intervention to facilitate solving any team conflicts. The second assessment occurs at the end of the semester and is used to weigh the final project grades based on each student's contribution to the project work.

\section{STUDENT TEAM FORMATION}

Although there are various methods that lecturers can follow to form engineering students design teams, they are far from perfect [13], and there is no consensus in the literature on the best approach to forming student teams [15]. Hence, the lecturer for the course under study decided to try two team formation approaches to figure out which approach would be more successful at fostering effective teams that allow students to learn and achieve their potential. The data collected for this article were gathered after the end of the semester, and the motivation for administering two team formation approaches was to improve the course rather than conduct research.

The lab sections were then divided into two groups. Students who signed up for the first group of labs were instructed to select their own team members and encouraged to select team members from different engineering disciplines and different years of study. We found that students chose their team members for a variety of reasons, including having worked together on past projects, because they were friends, because they perceived they would get along and simply for random reasons such as choosing the students that sat near them in the lab.

On the other hand, students who signed up for the second group of labs were put into teams by the course's instructor. The instructor initially wanted to create diverse teams by assigning the students using their OCEAN personality assessments while keeping in mind their year of study and their engineering discipline. However, when the students' OCEAN personality tests were conducted, it was found that the personalities of most students were similar. Most students in this class scored low in openness, high on conscientiousness and low in neuroticism. Moreover, the teams needed to be formed of students within one lab section (the maximum number of students in a lab is 24), further limiting the personality variation. As a result, the idea of choosing the teams based on personality types was dropped. Instead, the instructor formed diverse teams based on the students' year of study and their engineering discipline.
Students initially selected which lab sections they wanted based on their own schedule and availability. However, the students were given the choice of switching lab sections to choose between a self-selected team and an instructor-selected one.

\section{METHODOLOGY}

\subsection{Participants}

The present study aims to understand how team formation approaches affect engineering students' academic achievement in collaborative project-basedlearning courses. The participants for this study were engineering students registering for an introduction to engineering design and product development course. The independent variable in this study was the team formation approach. Dependent variables were the teams' project marks, the students' peer assessment score and the students' final marks. Data were collected from an introduction to engineering design and product development course that was taught in the fall semester of the 2018-2019 academic year. There were 57 students registered for the course and 15 teams formed. The number of students per year of study is shown in Table I below.

Table I - Number of Students per Year of Study

\begin{tabular}{|l|l|}
\hline Year of Study & Number of Students \\
\hline First Year & 7 \\
\hline Second Year & 42 \\
\hline Third Year & 3 \\
\hline Fourth Year & 4 \\
\hline Special Student & 1 \\
\hline Total & 57 \\
\hline
\end{tabular}

\subsection{Instruments}

\subsubsection{Peer and Team Dynamics Assessment}

At the start of the course, a lecture was dedicated to providing teamwork skills training to students. Students then either selected their team members or had them assigned by the professor. Each team outlined their 
acceptable teamwork norms in a contract, and each team member signed the contract. At the end of the semester, students rated their peers' contribution to the project. The peer assessment was done using an online tool developed by the Individual and Team Metrics Lab at the University of Calgary. The peer assessment tool - which is based on Ohland et al.'s [16] Comprehensive Assessment of Team Member Effectiveness [14] dimensions: communication, commitment, knowledge, skills and abilities, standards, and keeping the team on track — invites students to rate each other on a 5-point Likert scale and provide personal feedback. The tool provides each student with a peer rating average score that ranges from 0 to 5 . Students also respond to a team dynamics assessment tool that generates a team dynamics score that ranges from 0 to 5 . The team dynamics assessment is based on a developmental model with four key teamwork skills communicate, adapt, relate and educate (CARE) - and is used to provide teams with specific information on the effectiveness of their team and an assessment of their team's state of functioning [17]. The tool generates a report that presents students with anonymized feedback from their peers. Students then use this report in developing an action plan to improve on their strengths and weaknesses. This team debrief session is held at one of the lab sessions.

\subsubsection{Project Manager Assessment}

Project managers are students in their third or fourth year of study who have taken this design course in a previous year and have demonstrated outstanding teamwork, communication and leadership skills. In each lab section, one or two project managers were assigned to help the students throughout the semester with their specific projects. The project managers were tasked with evaluating students' contribution to their project work at the end of the semester, based on five criteria: teamwork, professionalism, communication, organization and discipline, and technical contribution. Each student was graded out of 5 for each criterion, for a possible total of 25 points. Each team of two project managers discussed the evaluation between themselves during the last lab session of the semester and awarded each student in their lab session points based on their participation and behavior during the semester.

\subsubsection{Student Satisfaction Survey}

A survey was sent to all the participants to get more feedback on their team experience throughout the semester. There were eight questions: one was an identifier, two were about reasons for a good or bad team experience, one was for general comments, and the rest asked the students to rate on a Likert scale from 1 to 5 their satisfaction with their teammate's contribution and professionalism, the choice of project, the prototype quality and the general experience in the team.

\subsubsection{Interviews}

Semi-structured interviews were conducted with four groups after the semester. Interviews lasted an average of 15 minutes. The purpose of the interviews was to identify the way each group managed their project, the challenges or problems they faced and how those were dealt with. Students were asked about the key points they retained from the semester in terms of what they had learned, as well as how much they liked the project and working with their teammates. Students were also asked if they had a leader and when that person was identified, as well as how they defined the scope of their project.

\section{RESULTS}

Table II presents descriptive statistics for the dependent variables under study. The course's final mark was out of 100, and the project's mark was out of 25 .

Table II - Descriptive Stats for Dependent Variables

\begin{tabular}{|l|l|l|l|}
\hline $\begin{array}{l}\text { Dependent } \\
\text { Variable }\end{array}$ & $\begin{array}{l}\text { No. of } \\
\text { Cases }\end{array}$ & Mean & $\begin{array}{l}\text { Standard } \\
\text { Deviation }\end{array}$ \\
\hline $\begin{array}{l}\text { Peer } \\
\text { Assessment }\end{array}$ & 54 & 4.24 & 1.01 \\
\hline $\begin{array}{l}\text { Project } \\
\text { Manager's } \\
\text { Marks }\end{array}$ & 56 & 21.38 & 5.12 \\
\hline $\begin{array}{l}\text { Students' } \\
\text { Final Mark }\end{array}$ & 56 & 76.16 & 15.28 \\
\hline $\begin{array}{l}\text { Team } \\
\text { Dynamics } \\
\text { Score }\end{array}$ & 13 & 4.23 & 0.69 \\
\hline $\begin{array}{l}\text { Team's } \\
\text { Project } \\
\text { Mark }\end{array}$ & 15 & 28.44 & 2.29 \\
\hline
\end{tabular}

\subsection{Team Analysis}

A Kruskal-Wallis test was conducted to determine if there were differences in team dynamics scores and in project marks between student teams that differed in their formation method: self-assigned teams $(n=8)$ and instructor-assigned teams $(n=7)$. Distributions of team dynamics scores and project marks were not similar for all 
groups, as assessed by visual inspection of the boxplot. The mean rank of team dynamics scores was not statistically significantly different between groups, $\chi 2(1)=0.021, p=.883$. The test also revealed there were no statistically significant differences in teams project marks based on team formation approach, $\chi^{2}(1)=1.085$, $\mathrm{p}=.298$. These results indicate there were no statistically significant differences between self-assigned teams and instructor-assigned teams in their team dynamics scores and project marks.

\subsection{Individual Students Analysis}

We also assessed if there were any statistically significant differences between the students' peer assessment scores, project manager marks and final marks based on how their team was formed. The data were not normally distributed, and there were multiple genuine outliers. We elected to administer a non-parametric test to analyze if there was a difference between the students' peer assessment scores, project manager marks and final marks based on their team's formation approach. The numbers of students used in the tests vary slightly, because a few marks were missing. One student, for example, did not complete a peer assessment.

A Kruskal-Wallis test was conducted to assess differences in peer assessment between students in selfselected teams $(n=29)$ and students in instructor-assigned teams $(n=25)$. The distribution of peer assessment marks was similar for all groups, as assessed by visual inspection of the boxplot. The mean rank of peer assessment was not statistically significant between groups, $\chi 2(1)=0.093, p=.760$.

The same test was done for the difference in PM marks between self-selected teams $(\mathrm{n}=30)$ and students in instructor-assigned teams $(n=26)$. The distribution of the PM marks was not similar for all groups, as assessed by a visual inspection of the boxplot. The mean rank differences of the PM mark were statistically significantly different between groups, $\chi 2(1)=13.433, \mathrm{p}=.000$.

Again, a Kruskal-Wallis test was conducted to assess the differences in final marks between students in selfselected teams $(n=29)$ and students in instructor-assigned teams $(n=27)$. The distribution of the students' final marks was similar for all groups, as assessed by visual inspection of the boxplot. The mean rank of the final marks was not statistically significant between groups, $\chi 2(1)=0.689, \mathrm{p}=.406$.
These results indicate there were no statistically significant differences between students in self-assigned teams and instructor-assigned teams in their contribution to their team work as assessed by the students' peer assessment. Nor were there statistically significant differences between students in the two groups under study in their academic achievement in the course as measured by their final marks. However, there was a significant difference in students' PM marks. This difference was significant only between one lab section and the other labs.

\subsection{Survey Analysis \& Group Interviews}

The survey had 28 respondents - 17 from selfassigned teams and 11 from instructor-assigned teams. A Fischer's exact test was conducted between the students' team formation approach (self-selected or instructorassigned) and each of the five Likert scale survey questions (satisfaction with the level of contribution of teammates, professionalism of teammates, project choice, prototype quality and team experience). There was no statistically significant difference in students' responses to the questions between students in self-assigned teams and those in instructor-assigned teams, with $\mathrm{p}=.442 ; .630$; $.490 ; .874 ; .829$ respectively for the five questions.

The student's satisfaction with their team experience was compared with two other questions from the survey: project choice and prototype quality. Between the satisfaction of project choice and team experience, there was no statistically significant association as assessed by Fisher's exact test, $\mathrm{p}=.190$. However, there was a statistically significant association between students' satisfaction with their prototype quality and their teamwork experience as assessed by Fisher's exact test, $p$ $=.007$. This indicates that when students had a positive teamwork experience, they were more likely to be satisfied with their prototype quality.

Four teams were interviewed about their learning experience in the course - two teams from each group (self-assigned teams and instructor-assigned teams). One team from each group was a high-performing team (received a $90 \%+$ on their project mark), and the other was an average-performing team (received a $70 \%$ on their project mark).

Based on the interviews we noticed that averageperforming teams were late to assign a leader and often failed to develop a weekly plan of action and a task list 
when compared with high-performing teams that had assigned a leader from the first week. For highperforming teams, team members were more aware of their skills, and the leader was selected by agreement on leadership skill level. Leaders in average-performing teams emerged through necessity, as teams lacked organization and were behind on their project work by mid-semester. Consistent with our quantitative analysis of student marks and the survey results, the interviews revealed that team formation approach had no significant impact on students' experience. However, all student teams interviewed — with the exception of the highperforming team in the self-assigned group — noted that they prefer to be assigned by their professor to a team for reasons such as preferring not to work with friends because they might not have a strong work ethic or because they feared it might affect their relationship, as well as the fear of choosing to work in a team or with a student with a weak work ethic as a consequence of not knowing any of the students who are registered in the course. It should be noted that the high-performing team in the self-assigned group that indicated they prefer to choose their own team members consisted of students who were high-achieving students, and some of them had prior experience working together. Their preference to choose their own teammates stemmed from a negative prior experience where their teammates didn't contribute to the project work.

Notably, all teams said they enjoyed the learning experience they had during the course and that it had a positive impact on their experience at the University of Ottawa.

\section{DISCUSSION}

In this study, we assessed if the team formation methods in an introductory collaborative project-basedlearning course on engineering design and product development had an impact on students' academic achievement in the course. We found that the approach to team formation had no impact on the teams' project marks, team dynamics scores, individual students' peer assessment marks or final marks in the course.

However, team formation approach revealed a significant difference in students' PM marks between selfassigned teams and instructor-assigned teams. This difference was caused by one lab section of the selfassigned teams that had received a mean PM mark of 24 out of 25. We followed up with interviews with the TA and PM of the lab sections of the course to understand the reason behind this difference and to assess if there was any bias in the PM assessments of the students' contribution. From the interviews, we realized that the reason for the significant difference was prior exposure to a similar learning experience, as the students who signed up for this lab section were mostly civil engineering students who had taken a prerequisite engineering design course prior to the course under study and were more prepared than other students in other lab sections to work in team environments. Their prior experience in a similar course allowed them to better participate in the labs and consequently receive a better PM mark because PMs rate students based on their participation and involvement in the project work during the lab hours. This result also revealed a caveat in the $\mathrm{PM}$ assessment, as it showed that it had failed to capture the students' involvement in the project work outside of lab hours, which was better captured by students' peer assessment marks. However, our finding is consistent with the other results of this study in that the team formation approach had no impact on students' academic achievement.

Takai \& Esterman [15] proposed a model that explains the potential associations between team inputs (team composition), team process (design activities) and team outputs (product performance and creativity of the solution); their model shows that the team formation approach and the design problem will affect the work structure and team characteristics. In turn, the team's work structure and characteristics will affect team collaboration and design processes, which in turn will affect the team's performance.

Figure I - Takai \& Esterman Design-Team Effectiveness Model [15]

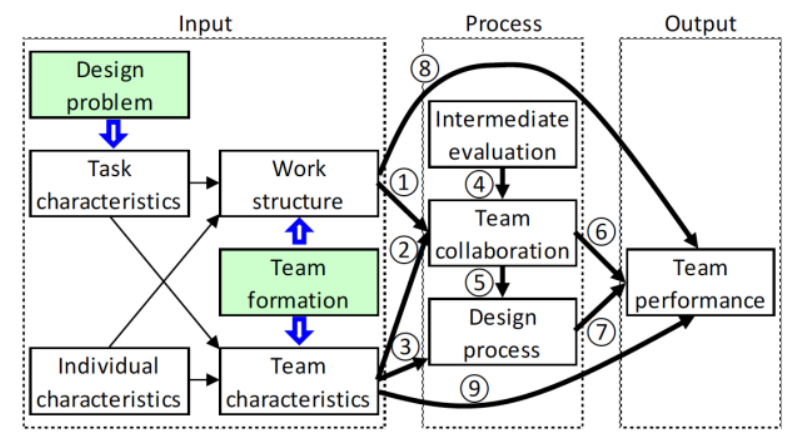

Although our findings contradict Takai \& Esterman's model, we hypothesize that several factors unique to the 
course under study affected the students' work structure and, in turn, their team's performance. The course under study employs several scaffolding strategies [18] to ensure that students complete their project before the end of the course and that any issues or conflicts are resolved in a timely manner. These scaffolding strategies include providing students with training on communication and teamwork skills and conflict management, guiding students to follow a design methodology throughout the learning experience, assigning each team a project manager and teaching assistant who help the students with mentorship and with any problems they face during the semester, and removing barriers to learning and using new engineering tools by introducing students to technologies in a controlled environment. We hypothesize that all these factors might have contributed to eliminating any differences in performance that might have been caused by the team formation approach. A comparative experimental study is required to assess if the team formation approach indeed has no impact on collaborative project-based-learning courses or if this result is unique to this course and to assess if a relationship exists between these scaffolding strategies and the team formation approach followed in the course.

Students' satisfaction with their team members' contribution and professionalism did not differ between teams that were self-assigned and those that were formed by the professor. Interviews, however, revealed that average- and below-average-performing students in both groups (self-assigned and instructor-assigned) preferred to be matched by a professor, and that the students in the high-performing team in the self-assigned group preferred to choose students they considered to have a high working ethic. This finding is consistent with findings about selfassignment, as students to tend to select students who are close to their own ability level [10, p. 69].

Interviews also revealed an association between students' satisfaction with their final prototype quality and their satisfaction with the course. This finding indicates that a positive team experience contributes to students' satisfaction with the quality of their prototype. Establishing a relationship between the quality of the prototype itself and students' satisfaction with their team experience warrants further research. Surprisingly, students' satisfaction with their project choice had no association with their satisfaction with their team experience.
The emergence of a leader in student teams was found to be a predictor of the team's performance, given that the high-performing teams were the ones to assign a leader. However, team formation was not a factor in teams' assigning a leader role to a student; rather, it was the students' work ethic and overall academic achievement. Teams composed of high-performing students regardless of the approach used to form the team - had assigned a leader from the beginning of the course, while average-performing teams lagged behind in assigning a leader. Although self-assigned teams are known to have a cold start [19], we found that even average-performing teams assigned by the professor lagged behind in assigning a team member.

\section{CONCLUSION}

The study's major findings about the collaborative project-based-learning course studied here is that team formation approach had no impact on the students' and teams' academic performance. We also found that students' satisfaction with their team experience was associated with their satisfaction with the quality of their prototype, while students' satisfaction with their project choice had no association with their satisfaction with their team experience. Moreover, we found that teams that had assigned a leader from the beginning of the course achieved higher results than those that assigned a leader midway through the course. This final finding suggests a recommendation to instructors teaching collaborative project-based-learning courses to encourage and facilitate the assignment of a leader in student teams early in the course.

This study also suggests that further experimental research where more than one collaborative projectbased-learning course is considered would be useful to reach a conclusion that could be extended to the general population of collaborative project-based-learning engineering design courses.

This study is limited by the fact that data were collected from a previous semester and the authors of this article had limited control over the study design. Moreover, the study is limited by the sample size of the students who registered for one course and the fact that only one course was studied. 


\section{Acknowledgements}

This work is supported by the Natural Sciences and Engineering Research Council of Canada (Chair in Entrepreneurial Engineering Design).

\section{References}

[1] T. Samuel, S. Toni, R. Pamela, and A. Digby, Cooperative Learning: A Guide To Research. New York: Garland Pub, 1991.

[2] R. T. Johnson and D. W. Johnson, "Action Research: Cooperative Learning in the Science Classroom on JSTOR," Sci. Child., vol. 24, no. 2, pp. 31-32, 1986.

[3] P. Dillenbourg, "What do you mean by collaborative learning?," in Collaborative Learning: Cognitive and Computational Approaches, P. Dillenbourg, Ed. Oxford: Elsevier, 1999, pp. 1-19.

[4] R. Felder and R. Brent, "Cooperative Learning in Technical Courses: Procedures, Pitfalls, and Payoffs.," Oct. 1994

[5] P. Race, The Lecturer's Toolkit. Routledge, 2014.

[6] B. Oakley, R. Brent, R. M. Felder, and I. Elhajj, "Turning student groups into effective teams," $J$. Student Centered Learn., pp. 9-34, 2004.

[7] J. A. Mello, "Improving individual member accountability in small work group settings," J. Manag. Educ., 1993.

[8] K. Deibel, "Team formation methods for increasing interaction during in-class group work," in Proceedings of the 10th Annual SIGCSE Conference on Innovation and Technology in Computer Science Education ITiCSE' '05, 2005, vol. 37, no. 3, p. 291.

[9] M. E. Natishan, L. C. Schmidt, and P. Mead, "Student Focus Group Results on Student Team Performance Issues," J. Eng. Educ., 2000.

[10] D. R. Bacon, K. A. Stewart, and S. Stewart-Belle, "Exploring Predictors of Student Team Project Performance," J. Mark. Educ., vol. 20, no. 1, pp. 6371, Apr. 1998.

[11] R. Decker, "Management Team Formation for Large Scale Simulations," Dev. Bus. Simul. Exp. Learn. Proc. Annu. ABSEL Conf., vol. 22, no. 0, Mar. 1995.

[12] D. R. Bacon, K. A. Stewart, and W. S. Silver, "Lessons from the Best and Worst Student Team Experiences: How a Teacher can make the Difference," J. Manag. Educ., vol. 23, no. 5, pp. 467-488, Oct. 1999.

[13] S.-T. Shen, S. D. Prior, A. S. White, and M. Karamanoglu, "Using personality type differences to form engineering design teams," Eng. Educ., vol. 2, no. 2, pp. 54-66, Dec. 2007.

[14] T. O'Neill et al., "Peer Ratings and Intentions to Change: Adopting the CATME to Explore Outcomes of Peer Ratings: American Society for Engineering
Education," in ASEE Annual Conference and Exposition, Conference Proceedings. , 2015.

[15] S. Takai and M. Esterman, "Towards a Better Design Team Formation: A Review of Team Effectiveness Models and Possible Measurements of Design-Team Inputs, Processes, and Outputs," in ASME 2017 International Design Engineering Technical Conferences and Computers and Information in Engineering Conference, 2017.

[16] M. W. Ohland et al., "The Comprehensive Assessment of Team Member Effectiveness: Development of a Behaviorally Anchored Rating Scale for Self- and Peer Evaluation," Acad. Manag. Learn. Educ., vol. 11, no. 4, pp. 609-630, Dec. 2012.

[17] N. L. Larson, G. Hoffart, T. A. O'Neill, W. Rosehart, R. Brennan, and M. Eggermont, "Team CARE model: Assessing team dynamics in first-year engineering student teams," in Annual Conference of the American Society for Engineering Education, 2015.

[18] M. Galaleldin, H. Anis, P. Dumond, and D. Knox, "Scaffolding strategies for teaching engineering design in a collaborative project-based learning environment" Proc. Can. Eng. Educ. Assoc., 2018.

[19] F. Jahanbakhsh, W.-T. Fu, K. Karahalios, D. Marinov, and B. Bailey, "You Want Me to Work with Who? Stakeholder Perceptions of Automated Team Formation in Project-based Courses," in Proceedings of the 2017 CHI Conference on Human Factors in Computing Systems - CHI '17, 2017, pp. 3201-3212.

\section{APPENDIX A}

Student satisfaction survey questions:

1. How satisfied were you with the level of contribution of your teammates?

2. How satisfied were you with the level of professionalism of your teammates?

3. How satisfied were you with the choice of project?

4. How satisfied were you with the prototype quality?

5. How was your experience in general in your team?

6. How could your experience have been improved if it was not great?

7. What factors contributed to your experience if it was good?

8. Do you have any other comments you would like to share? 